\title{
Inhibition versus activation of canonical Wnt-signaling, to promote chondrogenic differentiation of Mesenchymal Stem Cells. A review.
}

\author{
Nikitas P. Schizas ${ }^{1}$ (D) ${ }^{\text {, }}$ Christos Zafeiris ${ }^{1}$, Anna-Aikaterini Neri ${ }^{1}$, Panagiotis P. Anastasopoulos ${ }^{2}$, Nikolaos A. \\ Papaioannou', Ismene A. Dontas \\ ${ }^{1}$ Laboratory for Research of the Musculoskeletal System, KAT Hospital, School of Medicine, National and Kapodistrian University of Athens, 2 The \\ Reading Shoulder Unit, Royal Berkshire Hospital NHS FT \\ Keywords: chondrogenesis, differentiation, mesenchymal stem cells, canonical wnt signaling \\ https://doi.org/10.52965/001c.27098
}

\section{Orthopedic Reviews}

Vol. 13, Issue 1, 2021

\begin{abstract}
Canonical Wnt signaling regulation is essential for controlling stemness and differentiation of mesenchymal stem cells (MSCs). However, the mechanism through which canonical Wnt-dependent MSC lineage commitment leads to chondrogenesis is controversial. Some studies hypothesize that inhibition of canonical Wnt signaling induces MSC chondrogenic differentiation, while others support that the pathway should be activated to achieve MSC chondrogenesis. The purpose of the present review is to analyze data from recent studies to elucidate parameters regarding the role of canonical Wnt signaling in MSC chondrogenic differentiation.
\end{abstract}

\section{INTRODUCTION}

Researchers have dedicated much effort to improving hyaline cartilage regeneration. Still, restoration of the native articular cartilage remains a challenging task. One therapeutic approach for cartilage repair is the utilization of mesenchymal stem cells (MSCs). MSCs are multipotent cells with the capacity to differentiate into the osteogenic, chondrogenic, and adipogenic lineages. ${ }^{1,2}$ They can be isolated from the bone marrow, adipose tissue, dental pulp, umbilical cord blood, and Wharton's jelly tissue. ${ }^{3-7}$ The multipotency they exhibit is an essential prerequisite for successful tissue engineering and regenerative medicine utilization. In particular, cartilage regeneration is an area that could greatly benefit from MSCs in the clinical field under appropriate conditions. A significant obstacle is the tendency of MSCs to differentiate toward the hypertrophic stage, forming transient, endochondral cartilage instead of stable, hyaline cartilage-like tissue. ${ }^{8}$

The canonical Wnt signaling pathway is widely studied and is known to play critical roles in skeletal development, ${ }^{9}$ implying potential involvement in cartilage homeostasis and repair. Several studies support the concept that Wnt signaling is essential for joint metabolism. A fine-tuned balance of canonical Wnt pathway activity is needed to prevent pathology in the articular cartilage. ${ }^{10}$ Optimal regulation of canonical Wnt pathway may be of great importance for cell-cell communication and in controlling stemness and differentiation in MSCs. However, the in vitro modulation towards lineage commitment by targeting canonical Wnt signaling in MSCs is controversial. Some authors hypothesize that inhibition of canonical Wnt signaling induces MSCs chondrogenic differentiation, while others design experimental studies hypothesizing that the pathway should be activated for this differentiation. Finally, both inhibiting ${ }^{11,12}$ and enhancing ${ }^{13}$ effects have been reported regarding the pathway's role in the process of chondrogenic differentiation.

The purpose of the present review is to analyze data from studies published during the last decade to elucidate the role of canonical Wnt signaling in MSC-generated hyaline cartilage restoration.

\section{INHIBITION OF CANONICAL WNT SIGNALING INDUCES CHONDROGENIC DIFFERENTIATION OF MESENCHYMAL STEM CELLS}

Several studies have demonstrated chondrogenic differentiation of MSCs by inhibition of canonical Wnt signaling. Moreira et al. treated bone marrow MSCs with high exogenous doses of Dickkopf-related protein 1 (DKK1), an extracellular inhibitor of the Wnt/ $\beta$-catenin pathway. The authors hypothesized that inhibition of the pathway in vitro

\footnotetext{
Corresponding author:

Name: Nikitas P. Schizas MD, MSc, PhD

Mailing address: Laboratory for Research of the Musculoskeletal System, KAT Hospital, School of Medicine, National and Kapodistrian University of Athens, Greece, 10 Athinas Street, 14561 Kifissia, Greece.

Telephone number: +306932683598.

E-mail: nikit.schizas@gmail.com
} 
would induce differentiation of bone marrow MSCs into a stable proliferative chondrocyte phenotype and prevent terminal cell differentiation through hypertrophy and cell death. Chondrogenic induction of human bone marrow MSCs was performed in a three-dimensional pellet culture system with ascorbic acid $37,5 \mathrm{ug} / \mathrm{mL}$ and transforming growth factor $\beta 1$ (TGF- $\beta$ 1) 10ng/mL. Pellet cells were cultured for 21 days. Two doses of DKK1, $50 \mathrm{ng} / \mathrm{ml}$, and 200 $\mathrm{ng} / \mathrm{ml}$ were added since the third day. A control group of pellets was cultured without DKK1 for 21 days. Pellets were analyzed at different times $(1,7,14$, and 21 days) by immunohistochemistry and protein expression. The authors concluded that treatment with 50 and $200 \mathrm{ng} / \mathrm{ml}$ of DKK1 reduced the pre-hypertrophic population to $46 \%$ and $30 \%$, respectively. Furthermore, DKK1 induced the expression of hyaline cartilage markers, COL2A1, and GAGs after 21 days of culture. ${ }^{14}$

Micro-ribonucleic acids (miRNAs) are a group of singlestranded, non-coding RNAs existing in eukaryotes. They bind to specific genes playing essential roles in the physiological activities of cells, such as proliferation, differentiation, and apoptosis. Zhang et al. studied micro-ribonucleic acid 410 (miR-410) and its effect on chondrogenic differentiation of MSCs in vitro. MSCs were obtained from 10 $\mathrm{ml}$ of bone marrow aspirates. The chondrogenic differentiation medium containing, among others, dexamethasone, ascorbate, and TGF- $\beta 3$ was replaced every 2 days. MiR-410 or miR-410 inhibitors were transfected into MSCs using lentivirus, and the effects were assessed. For transfection of MSCs with lentivirus, the cells were seeded in 6 well plates and incubated for 12 hours. The transfected miR- 410 significantly promoted chondrogenic differentiation through the Wnt signaling pathway. Luciferase assay revealed that the level of Wnt3a 3'UTR was reduced in miR-410 transfected MSCs, suggesting that miR-410 regulates Wnt3a expression by binding to the 3'UTR of the Wnt3a gene. The authors reported that miR-410 was increased during TGF- $\beta 3$-induced chondrogenic differentiation of MSCs. They finally concluded that miR-410 promoted chondrogenic differentiation of human bone marrow mesenchymal stem cells through down-regulating Wnt3a and inhibition of the Wnt signaling pathway. ${ }^{15}$

\section{BOTH OVEREXPRESSION AND OVER INHIBITION}

\section{OF CANONICAL WNT SIGNALING CAUSES}

\section{HARMFUL EFFECTS ON MSC CHONDROGENIC DIFFERENTIATION}

Huang X. et al. assessed the potential effects of small molecules on chondrogenic differentiating human mesenchymal stem cells (hMSCs) with continuous inhibition or activation of canonical Wnt signaling in vitro. hMSCs were isolated from bone marrow aspirates which were resuspended using a 20 Gauge needle, plated at a density of 0.5 million mononucleated cells $/ \mathrm{cm}^{2}$, and cultured in a hMSCs proliferation medium. They established pellet culture for three-dimensional chondrogenic differentiation of 5 weeks. Glycogen synthase kinase $3 \beta \quad$ inhibitor 6-bromoindirubin-3-oxime (BIO) was used to activate Wnt signaling and PKF118-310 (PKF) was used to inhibit the pathway, as it inhibits Wnt signaling by interfering with the binding of $\beta$-catenin to the transcription factor TCF4. The optimal concentration of BIO and PKF of 2 and $3 \mu \mathrm{M}$, respectively, was adopted in all subsequent experiments. The effects of BIO and PKF on the chondrogenesis of hMSCs were examined by real-time PCR, histological methods, and ELISA. According to their results, high levels of Wnt signaling inhibited the chondrogenic differentiation of hMSCs, evidenced by decreased SOX9, ACAN, and COL2A1 expression. Still, they promoted the hypertrophy of chondrocytes, as was shown by the enhanced expression of RUNX2, COL10A1, MMP13, and ALPL. In contrast, the authors reported that BIO significantly decreased the number of apoptotic cells, while PKF induced cell apoptosis. Conversely, low levels of Wnt signaling promoted hMSC chondrogenic differentiation and inhibited chondrocyte hypertrophy. In conclusion addition of BIO to the chondrogenic medium of hMSCs resulted in a loss of cartilage formation, while PKF induced chondrogenic differentiation and cartilage matrix deposition and inhibited hypertrophic differentiation. However, BIO promoted cell survival by inhibiting apoptosis while PKF induced cell apoptosis. This result indicates that either overexpression or over inhibition of Wnt signaling to some intermediate extent causes harmful effects on chondrogenic differentiation. ${ }^{16}$

\section{INHIBITION OF CANONICAL WNT SIGNALING INHIBITS CHONDROGENIC DIFFERENTIATION OF MESENCHYMAL STEM CELLS}

In an in vitro study, Huang T. et al. investigated the influence of micro-ribonucleic acid (miR)-26b on the cartilage differentiation of mesenchymal stem cells (MSCs) in rats and its mechanism. They isolated MSCs from the bone marrow and transfected them with micro-ribonucleic acid (miR)-26b. The study results revealed that the differentiation of MSCs into chondrocytes was significantly enhanced after the knockdown of miR-26b, mainly manifested as the upregulated mRNA and protein expression levels of Aggrecan and Collagen II. Moreover, target genes of miR-26b in rats were predicted using the bioinformatics technique, recognizing Wnt as one of the target genes of miR-26b. Specifically, miR-26b could directly inhibit the 3'untranslated region (3'UTR) of the Wnt gene in a targeted manner. Acknowledging the study's limitations, like the lack of verification by using human MSCs, the authors concluded that inhibition of the Wnt gene also inhibited the cartilage differentiation of MSCs. ${ }^{17}$

\section{ACTIVATION OF CANONICAL WNT SIGNALING INDUCES CHONDROGENIC DIFFERENTIATION OF MESENCHYMAL STEM CELLS}

Several studies support the concept of activating canonical Wnt signaling to induce MSC chondrogenesis. Tanthaisong et al. studied the combined effect of Glycogen synthase kinase $3 \beta$ (Gsk- $3 \beta$ ) inhibitors and TGF- $\beta 3$ on chondrogenic differentiation in hMSCs derived from a single individual's 
Wharton's jelly tissue (hWJ-MSCs). Gsk-3 $\beta$ inhibitors are compounds that activate the Wnt signaling pathway. This in vitro study investigated the aforementioned synergistic influence on MSCs by monolayer and pellet culture experiments. The differentiated cells were characterized by glycosaminoglycan (GAG) analysis, immunofluorescent staining, western blot, and gene expressions analysis. According to the authors' conclusions, the expression of collagen type II was strongly increased in the chondrogenic medium containing SB216763 as evidenced by western blot analysis. SB216763 also upregulated the expression of several genes, including ACAN, Col2a1, and Sox9.SB216763 was more effective than Lithium Chloride $(\mathrm{LiCl})$ treatment. In conclusion, Gsk-3 $\beta$ inhibitors induced the Wnt signaling pathway and promoted chondrogenic differentiation of hWJ-MSCs in the presence of TGF- $\beta 3$, without inducing chondrocyte hypertrophy. 18

Jothimani et al. tested the hypothesis that Wnt proteins regulate in vitro differentiation of human umbilical cordderived MSCs (hUCMSCs). The effects of a small molecule Wnt activator $(\mathrm{LiCl})$ and Wnt antagonist (Quercetin) were respectively evaluated in hUCMSCs after treatment for six days. Quercetin acts intracellularly, disrupting the interaction of $\beta$-catenin and Axin-1, while $\mathrm{LiCl}$ is also a Gsk-3 $\beta$ inhibitor acting intracellularly. Flow cytometric immunophenotyping of hUCMSCs for relevant markers and genes expression revealed downregulation in the expression of Wnt with Quercetin treatment. LiCl treatment increased cellular proliferation but did not influence differentiation, suggesting that the cells retain pluripotency. Quercetin treatment downregulated stemness markers, Wnt target gene expression, and promoted osteogenesis. Summarizing the impact of Wnt signaling on lineage commitment of MSCs, the authors concluded that a shift of differentiation potential after the inhibition of Wnt signaling by Quercetin was evident, driving MSCs towards the osteogenic lineage. ${ }^{19}$

Eslaminejad et al. investigated the effect of two Gsk-3 $\beta$ inhibitors on the GAG content of cartilage produced by human marrow MSCs during in vitro chondrogenesis. MSCs were centrifuged into small aggregates and provided with a chondrogenic medium supplemented with either $\mathrm{LiCl}$ or SB216763. Three weeks later, GAG contents of the culture were quantified and compared to each other and the control. Both $\mathrm{LiCl}$ and SB216763 treatment of chondrogenic culture prepared from human marrow-derived MSCs produced a statistically significant greater yield of GAG-rich extracellular matrix (ECM). The authors concluded that Wnt signaling activation by using Gsk-3 $\beta$ inhibitors in chondrogenic cultures could lead to the production of cartilage mass high in GAG content. ${ }^{20}$

In another study by Eslaminejad et al., the authors attempted to evaluate the enhancing effects of BIO, a Gsk-3 $\beta$ inhibitor, on the chondrogenic differentiation of MSCs extracted from the marrow of mice. According to their findings, cartilage-specific genes, including Sox9, aggrecan, and collagen II were in their maximum expression levels at day 14 of the cultures treated with BIO. In contrast, the expression level of these genes reached a maximum at day 21 of the control culture. In conclusion, BIO at $0.01 \mu \mathrm{M}$ could ac- celerate and enhance in vitro chondrogenesis of mouse marrow-derived MSCs. ${ }^{21}$

Yang et al. investigated the effect of TGF- $\beta$ and $\beta$ catenin signaling coactivation during MSC chondrogenic differentiation. Activation of $\beta$-catenin was achieved by using the well-documented Gsk-3 $\beta$ inhibitor, LiCl. Human bone marrow MSCs were differentiated in a chondrogenic medium that contained either TGF- $\beta$ alone, TGF- $\beta$ with transient $\beta$-catenin coactivation, or TGF- $\beta$ with continuous $\beta$-catenin coactivation. After in vitro differentiation, the pellets were transplanted into mice. The first 7 days' transient co-induction of TGF- $\beta$ and $\beta$-catenin coactivation was equally effective in enhancing MSC chondrogenic differentiation as continuous coactivation. When following up the hypertrophic development of the induced cells, differences in chondrogenic maturation between the transient and the continuous $\beta$-catenin coactivation samples were detected. Although transient coactivation did not show the apparent effect on hypertrophy development in vitro, a heightened development towards hypertrophy was detected after ectopic implantation apart from increased type X collagen deposition. Continuous coactivation of TGF- $\beta$ and $\beta$-catenin signaling induced MSC chondrogenesis resulted in a significant hypertrophy reduction, as evident from the downregulation of Col10 mRNA, the reduction in deposition of type X collagen, and alkaline phosphatase activity, with prolonged in vitro culture up to 5 weeks. The authors concluded that chondrocytes derived from the TGF- $\beta$ and $\beta$-catenin coactivated MSCs, having their hypertrophic development reduced, might retain a degree of plasticity that the niche environment can further mold at the articular cartilage site. $^{22}$

It has been reported that the co-culture of bone marrow mesenchymal stem cells (BMSCs) with chondrocytes induces their chondrogenic differentiation. ${ }^{23}$ The concept is that in a co-culture system, chondrocytes may secrete various factors to promote the chondrogenic differentiation of BMSCs. Li et al. firstly confirmed that chondrocyte-derived exosomal miRNA could induce the chondrogenic differentiation of BMSCs in a co-culture model. Specifically, they reported that miR-8485 was the exosomal miRNA derived from chondrocytes and transferred to BMSCs. Functional assays showed that miR-8485 silence in chondrocyte exosomes counteracted the exosome-induced chondrogenic differentiation of BMSCs, while overexpression of miR-8485 in BMSCs induced chondrogenic differentiation. Exosomal miR-8485 activated the Wnt/ $\beta$-catenin pathway by regulating Gsk-3 $\beta$ expression and phosphorylation. Specifically, miR-8485 overexpression reduced total Gsk-3 $\beta$ in BMSCs through DACT1-mediated p-Gsk-3 $\beta$ (Ser9), indicating that miR-8485 activated the $\mathrm{Wnt} / \beta$-catenin pathway through regulating both Gsk-3 $\beta$ expression and its activity. $^{24}$

In a New Zealand White (NZW) rabbit model study conducted in our laboratory, we investigated the effect of combining microfracture with Wnt/ $\beta$-Catenin pathway induction to treat experimentally generated cartilage defects. Based on previous in vitro studies, ${ }^{20,25}$ we hypothesized that the healing potential initiated in the microfracture clot 
Table 1. Summary of the published in vitro and animal studies.

\begin{tabular}{|c|c|c|c|c|}
\hline $\begin{array}{l}\text { AUTHORS/ } \\
\text { YEAR OF } \\
\text { PUBLICATION/ } \\
\text { TYPE OF } \\
\text { STUDY }\end{array}$ & $\begin{array}{l}\text { ORIGIN OF } \\
\text { MSCs }\end{array}$ & $\begin{array}{l}\text { WNT } \\
\text { SIGNALING } \\
\text { REGULATION }\end{array}$ & MECHANISM OF REGULATION & RESULT \\
\hline $\begin{array}{l}\text { Moreira et } \\
\text { al. }{ }^{14 / 2019 / \text { in }} \\
\text { vitro }\end{array}$ & $\begin{array}{l}\text { Bone } \\
\text { marrow }\end{array}$ & $\begin{array}{l}\text { Inhibition of } \\
\text { Wnt signaling }\end{array}$ & $\begin{array}{l}\text { DKK1(extracellular inhibitor of the } \\
\text { Wnt/ } \beta \text {-catenin pathway) }\end{array}$ & $\begin{array}{l}\text { Enhanced MSC } \\
\text { chondrogenesis }\end{array}$ \\
\hline $\begin{array}{l}\text { Zhang et al. }{ }^{15 /} \\
2017 / \text { in vitro }\end{array}$ & $\begin{array}{l}\text { Bone } \\
\text { marrow }\end{array}$ & $\begin{array}{l}\text { Inhibition of } \\
\text { Wnt signaling }\end{array}$ & $\begin{array}{l}\text { miR-410(negatively regulated its target } \\
\text { gene, Wnt3a) }\end{array}$ & $\begin{array}{l}\text { Enhanced MSC } \\
\text { chondrogenesis }\end{array}$ \\
\hline $\begin{array}{l}\text { Huang X. et } \\
\text { al. } 16 / 2018 / \text { in } \\
\text { vitro }\end{array}$ & $\begin{array}{l}\text { Bone } \\
\text { marrow }\end{array}$ & $\begin{array}{l}\text { Comparison of } \\
\text { overexpression } \\
\text { with } \\
\text { overinhibition } \\
\text { of Wnt } \\
\text { signaling }\end{array}$ & 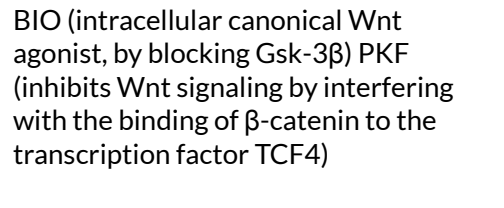 & $\begin{array}{l}\text { Either an } \\
\text { overexpression or } \\
\text { overinhibition of Wnt } \\
\text { signaling causes } \\
\text { harmful effects on } \\
\text { MSC chondrogenesis }\end{array}$ \\
\hline $\begin{array}{l}\text { Huang T. et } \\
\text { al. }{ }^{17} / 2019 / \text { in } \\
\text { vitro }\end{array}$ & $\begin{array}{l}\text { Bone } \\
\text { marrow }\end{array}$ & $\begin{array}{l}\text { Inhibition of } \\
\text { Wnt signaling }\end{array}$ & $\begin{array}{l}\text { miR-26b (inhibitor of the 3'untranslated } \\
\text { region of Wnt gene) }\end{array}$ & $\begin{array}{l}\text { Inhibited MSC } \\
\text { chondrogenesis }\end{array}$ \\
\hline $\begin{array}{l}\text { Tanthaisong et } \\
\text { al. } 18 / 2017 / \text { in } \\
\text { vitro }\end{array}$ & $\begin{array}{l}\text { Human } \\
\text { Wharton's } \\
\text { jelly tissue } \\
\text { (hWJ- } \\
\text { MSCs) }\end{array}$ & $\begin{array}{l}\text { Activation of } \\
\text { Wnt signaling }\end{array}$ & $\begin{array}{l}\text { SB216763 or LiCl (Gsk-3 } \beta \text { inhibitors } \\
\text { acted as intacellular agonists of Wnt } \\
\text { signaling) }\end{array}$ & $\begin{array}{l}\text { Enhanced MSC } \\
\text { chondrogenesis }\end{array}$ \\
\hline $\begin{array}{l}\text { Jothimani et } \\
\text { al. }{ }^{19 / 2020 / \text { in }} \\
\text { vitro }\end{array}$ & $\begin{array}{l}\text { Human } \\
\text { umbilical } \\
\text { cord } \\
\text { (hUCMSCs) }\end{array}$ & $\begin{array}{l}\text { Comparison of } \\
\text { Wnt signaling } \\
\text { activation with } \\
\text { Wnt signaling } \\
\text { inhibition }\end{array}$ & $\begin{array}{l}\text { Quercetin (intracellular inhibition of } \\
\text { Wnt through disruption of the } \\
\text { interaction of } \beta \text {-catenin and Axin-1) } \\
\text { LiCl (Gsk- } 3 \beta \text { inhibitor acted as } \\
\text { intacellular agonist of Wnt signaling) }\end{array}$ & $\begin{array}{l}\text { Inhibition of Wnt } \\
\text { signaling drove MSCs } \\
\text { towards osteogenic } \\
\text { lineage }\end{array}$ \\
\hline $\begin{array}{l}\text { Eslaminejad et } \\
\text { al. } 20 / 2011 / \text { in } \\
\text { vitro }\end{array}$ & $\begin{array}{l}\text { Bone } \\
\text { marrow }\end{array}$ & $\begin{array}{l}\text { Activation of } \\
\text { Wnt signaling }\end{array}$ & $\begin{array}{l}\text { SB216763 or LiCl (Gsk-3 } \beta \text { inhibitors } \\
\text { acted as intacellular agonists of Wnt } \\
\text { signaling) }\end{array}$ & $\begin{array}{l}\text { Enhanced MSC } \\
\text { chondrogenesis }\end{array}$ \\
\hline $\begin{array}{l}\text { Eslaminejad et } \\
\text { al. }^{21 / 2014 / \text { in }} \\
\text { vitro }\end{array}$ & $\begin{array}{l}\text { Bone } \\
\text { marrow }\end{array}$ & $\begin{array}{l}\text { Activation of } \\
\text { Wnt signaling }\end{array}$ & $\begin{array}{l}\text { BIO (intracellular canonical Wnt } \\
\text { agonist, by blocking Gsk-3ß) }\end{array}$ & $\begin{array}{l}\text { Enhanced MSC } \\
\text { chondrogenesis }\end{array}$ \\
\hline $\begin{array}{l}\text { Yang et al. } 22 \text { / } \\
2012 \text { / in vitro } \\
\text { and in vivo } \\
\text { animal study }\end{array}$ & $\begin{array}{l}\text { Bone } \\
\text { marrow }\end{array}$ & $\begin{array}{l}\text { Activation of } \\
\text { Wnt signaling }\end{array}$ & $\begin{array}{l}\mathrm{LiCl} \text { (Gsk-3 } \beta \text { inhibitor, acting as } \\
\text { intacellular agonist of Wnt signaling) }\end{array}$ & $\begin{array}{l}\text { Enhanced MSC } \\
\text { chondrogenesis }\end{array}$ \\
\hline $\begin{array}{l}\text { Li et al. }{ }^{24 /} \\
2020 / \text { in vitro }\end{array}$ & $\begin{array}{l}\text { Bone } \\
\text { marrow }\end{array}$ & $\begin{array}{l}\text { Activation of } \\
\text { Wnt signaling }\end{array}$ & $\begin{array}{l}\text { miR-8485 (Reduction of Gsk-3 } \beta \\
\text { expression and activity) }\end{array}$ & $\begin{array}{l}\text { Enhanced MSC } \\
\text { chondrogenesis }\end{array}$ \\
\hline $\begin{array}{l}\text { Schizas et al. }{ }^{26 /} \\
\text { 2019/in vivo } \\
\text { animal study }\end{array}$ & $\begin{array}{l}\text { Bone } \\
\text { marrow }\end{array}$ & $\begin{array}{l}\text { Activation of } \\
\text { Wnt signaling }\end{array}$ & $\begin{array}{l}\mathrm{LiCl} \text { (Gsk-3 } \beta \text { inhibitor, acting as } \\
\text { intacellular agonist of Wnt signaling) }\end{array}$ & $\begin{array}{l}\text { Enhanced MSC } \\
\text { chondrogenesis }\end{array}$ \\
\hline
\end{tabular}

The order of study presentation of Table 1 is in accordance to the order of study citation in the text.

through the proliferation of pluripotent mesenchymal progenitor cells, with a capacity to differentiate into multiple mesenchymal cell types, could be amended by the chondrogenic differentiation effect of Lithium as a Gsk-3 $\beta$ inhibitor. Induction of the canonical Wnt pathway was achieved by administering Lithium carbonate in a concentration of $7 \mathrm{mM}$. We incorporated two experimental groups treated with microfracture and per os administration of Lithium for one or four weeks and compared them with a third control group treated with microfracture only. The comparison was conducted in terms of the International Cartilage Repair Society (ICRS) visual histological scale scoring and immunohistochemistry for type II collagen. The conclusion was that induction of the Wnt/ $\beta$-catenin sig- naling pathway for 4 weeks after application of microfracture resulted in significantly statistical superiority in four out of six histological ICRS categories compared to the control group. The 1-week treatment group was superior to the control group in two out of six ICRS categories. ${ }^{26}$

The aforementioned studies are summarized in Table 1.

\section{DISCUSSION}

The Wnt/ $\beta$-catenin pathway is activated when a Wnt ligand binds to a transmembrane Frizzled (Fz) receptor and its co-receptor, low-density lipoprotein receptor-related protein 5/6 (LRP5 or LRP6). The formation of a Wnt-Fz-LRP5/6 
complex and the recruitment of the scaffolding protein Dishevelled (Dvl) results in LRP6 phosphorylation and activation and the recruitment of the Axin complex the receptors. The Axin complex comprises the scaffolding protein Axin, the tumor suppressor adenomatous polyposis coli gene product (APC), casein kinase 1 (CK1), and Gsk-3 $\beta$, which is a key regulator of the canonical Wnt pathway. ${ }^{27}$

In the absence of appropriate Wnt ligands, a destruction complex comprising Axin and Adenomatous polyposis coli (APC) mediates the phosphorylation of $\beta$-catenin by Gsk-3 $\beta$ which leads cytosolic $\beta$-catenin to degradation by the proteasome. (Figure 1)

Inhibition of Axin-mediated $\beta$-catenin phosphorylation leads to the stabilization of $\beta$-catenin, which accumulates in cytoplasmic pools and travels to the nucleus, forming complexes with TCF/LEF and activates Wnt target gene expression. ${ }^{27}$ (Figure 2) Canonical Wnt signaling seems to be coordinated in three levels: extracellular, cytoplasmic, and intranuclear.

Several secreted protein families antagonize or modulate Wnt/ $\beta$-catenin signaling at the extracellular level. In particular, secreted Frizzled related proteins (sFRPs) and Wnt inhibitory protein (WIF) bind to Wnt, and in the case of sFRPs, also to $\mathrm{Fz}$ and thereby function as Wnt antagonists. ${ }^{28}$ Two distinct categories of Wnt inhibitors are the Dickkopf (Dkk) and the Wise/SOST families, acting as FzLRP5/6 complex antagonists. ${ }^{29}$ Furthermore, the potential participation of these components in interactive feedback loops, regularly incorporated in self-regulation and homeostasis of cells, shapes a complex framework.

The plethora of agonists and antagonists of Wnt signaling at the extracellular level, given the requirement for precise fine-tuning of the pathway during chondrogenic differentiation of MSCs, raises uncertainty regarding experimental interventions targeted to these factors. This context is highlighted by comparing data from the studies by Moreira et al. ${ }^{14}$ and Jothimani et al. ${ }^{19}$ Both studies tested the effect of Wnt signaling inhibition on MSC chondrogenic differentiation, incorporating different inhibitors. In the first case, utilization of an extracellular inhibitor favored chondrogenesis, but in the second the intracellular Wnt inhibitor induced osteogenesis. Taken together, these findings cause uncertainty regarding the result of inhibiting the pathway. A possible explanation mainly concerning extracellular Wnt inhibitors is that several Wnt proteins have been shown to participate in the canonical Wnt pathway; however, their effects on chondrogenesis vary. Wnt1, Wnt4, and Wnt8 inhibit chondrogenic differentiation, while Wnt3a and Wnt5b stimulate it. Additionally, chondrocyte hypertrophy is inhibited by Wnt3a and Wnt5b, whereas Wnt 4 and Wnt8 stimulate it. ${ }^{30-33}$ The study by Zhang et al. also confirms the previous data, as miR-410 induced chondrogenic differentiation of human bone marrow mesenchymal stem cells through down-regulating Wnt3a. ${ }^{15}$

Although Wnt signaling can both activate and inhibit chondrogenic differentiation of progenitor cells, the study by Huang $\mathrm{T}$. et al. offers essential evidence regarding the effect of inhibiting the pathway. ${ }^{17}$ They reported that miR-26b plays an inhibitory role in the in vitro cartilage differentiation of rat MSCs by inhibiting Wnt expression, thus
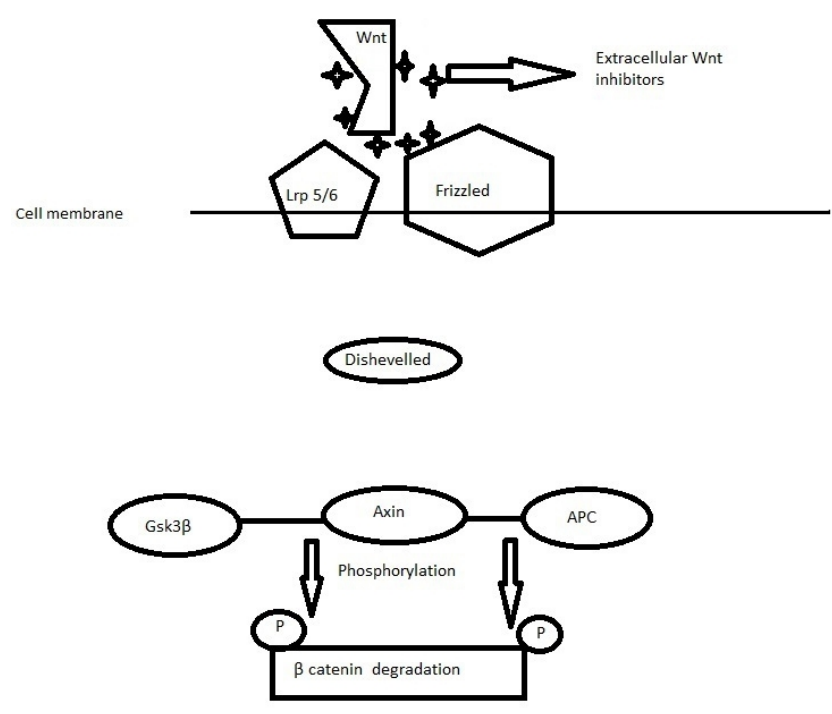

Nucleus

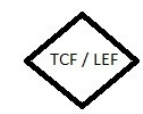

Figure 1. In the absence of appropriate Wnt ligands cytosolic $\beta$-catenin undergoes degradation by the proteasome.

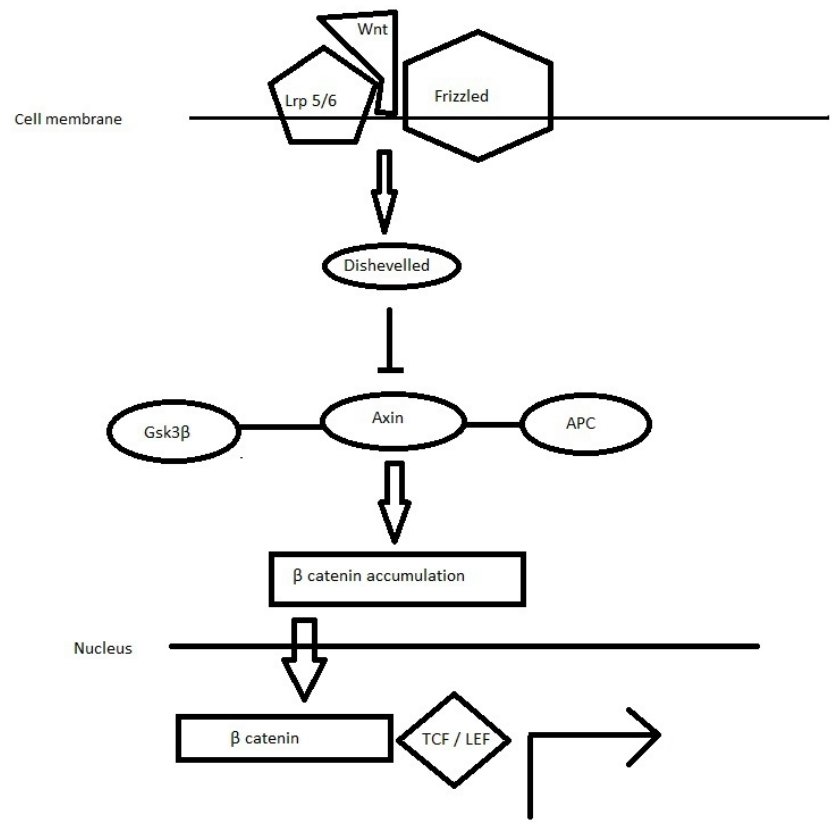

Figure 2. When a Wnt ligand binds to a transmembrane Frizzled receptor and its coreceptor LRP5 and LRP6, $\beta$-catenin travels to the nucleus, where it forms complexes with TCF/LEF and activates Wnt target gene expression.

stating that at least a minimum level of active Wnt signaling is required to allow MSC chondrogenesis.

These antagonistic effects may finally reach a concluding result regarding lineage commitment in synergy with a va- 
riety of factors, including the phase of differentiation of target cells, level of Wnt activity, and particular type of Wnt signal. ${ }^{34}$

The intensity of the Wnt signal modification affecting MSC chondrogenic differentiation also determines the final outcome. According to the study by Huang X. et al., ${ }^{16}$ either overexpression or over inhibition of Wnt signaling causes harmful effects on chondrogenic differentiation. The authors incorporated Gsk-3 $\beta$ inhibitor 6-bromoindirubin-3-oxime (BIO) to activate Wnt signaling in a concentration of $2 \mu \mathrm{M}$ in all subsequent experiments. Interestingly in the study by Eslaminejad et al., ${ }^{21}$ utilization of the same reagent but lower concentrations did not have the same result, as BIO at $0.01 \mu \mathrm{M}$ accelerated and enhanced in vitro chondrogenesis mouse marrow-derived MSCs. The study by Tanthaisong et al. also offers important data regarding the optimal intensity of signal modification. ${ }^{18}$ hWJ-MSCs treated with $\mathrm{LiCl}$ presented reduced viability in a dose-dependent manner. In the presence of $5 \mathrm{mM} \mathrm{LiCl}$, cell viability was significantly higher than that in 10 and $20 \mathrm{mM} \mathrm{LiCl}$, respectively. These results indicated that high $\mathrm{LiCl}$ concentrations, 10 and $20 \mathrm{mM}$, could induce hWJ-MSC death. The same pattern is confirmed with the usage of a different Gsk-3 $\beta$ inhibitor, SB216763. In the presence of $1 \mu \mathrm{M}$ SB216763, cell viability was significantly higher than that in the presence of 2.5 and $5 \mu \mathrm{M}$, respectively.

Additionally, in the animal proof of concept study from our lab, the study groups received treatment with lithium carbonate of $7 \mathrm{mM}$ in the drinking water for 1 or 4 weeks as an intracellular activator of Wnt signaling. This treatment protocol resulted in serum lithium concentrations of $0.40 \pm 0.20 \mathrm{mM} / \mathrm{L}$ (mean $\pm \mathrm{SEM}$ ), relatively stable at weeks 1 and 4 . These serum levels are slightly lower than the range of $0.6-1.2 \mathrm{mM} / \mathrm{L}$, concentrations achieved and maintained during lithium therapy in human subjects. ${ }^{26}$ This ostensibly low serum concentration was enough to induce chondrogenic differentiation of the bone marrow-derived MSCs accumulated inside the microfracture clot. In the case of extracellular Wnt inhibitors, a dose-dependent effect is also observed, as the higher dose of DKK1 resulted in a $30 \%$ reduction of the pre-hypertrophic population, whereas the lower amount reduced the pre-hypertrophic population by $46 \% .^{14}$

Answering which intervention during MSC differentiation favors their commitment to the chondrogenic lineage could be achieved through several strategies. One is studies designed based on literature-supported hypotheses regarding concepts already established in embryology or developmental biology. Another strategy is an etiological approach to the question, which would investigate a procedure proven to induce MSC chondrogenic differentiation to define the components responsible for the result. Such a strategy would allow linking a specific component or reagent to the desired outcome in an etiological manner. This concept was encountered in the study by $\mathrm{Li}$ et al. ${ }^{24}$ where a co-culture model was studied to define the reagent that guided MSCs towards chondrogenesis. They first reported that miR-8485 was the exosomal miRNA transferred from chondrocytes to co-cultured MSCs, leading to their chondrogenic commitment. Afterward, they proved that the micro-ribonucleic acid's target in MSCs was Gsk-3 $\beta$. Finally, they reached a solid conclusion indicating that activation of the Wnt/ $\beta$-catenin pathway through inhibiting both Gsk-3 $\beta$ expression and activity favored the chondrogenic differentiation of MSCs.

Regarding the optimal duration of Wnt signaling modification, Yang et al. reported that TGF- $\beta$ and $\beta$-catenin signaling coactivation during MSC chondrogenic differentiation for seven days resulted in different cartilage phenotypes, compared to a prolonged in vitro coactivation of up to 5 weeks. ${ }^{22}$ The continuous coactivation of the two signaling pathways resulted in inhibition of progression to chondrocyte hypertrophy. They finally hypothesized that chondrocytes derived from the $\beta$-catenin activated MSCs, having their hypertrophic development reduced, might retain a degree of plasticity that the niche environment could further mold at the articular cartilage site. These findings are also supported by data from our animal model, as induction of Wnt signaling during only the first-week post microfracture was not sufficient to exert the beneficial effect of the 4-week treatment upon the histological properties of the repair tissue. ${ }^{26}$

Potential limitations of utilizing Wnt signaling activation in clinical practice originate from the consideration that this process could increase the possibility of susceptibility to carcinogenesis. Constitutive Wnt activation by genetic mutation of intracellular signaling components such as $\beta$-catenin has been shown to cause tumors in several tissues, including the liver and colon. ${ }^{35}$ Moreover, according to a recent study, canonical Wnt signaling has been functionally linked to the Hedgehog $(\mathrm{Hh})$ signaling pathway in MSC proliferation and differentiation, skeletal growth, and tumor formation. Specifically, Hh signaling executes its pleiotropic effects via increasing the expression of a couple of Wnt molecules and enhancing Wnt/ $\beta$-Catenin activation, suggesting that enchondroma and osteosarcoma are derived from early progenitors of chondrocytes and osteoblasts. ${ }^{36}$ Such concerns can be transcended as Lithium, which is a Wnt signaling activator, has been used for decades to treat psychiatric illnesses in humans without being associated with an apparent increase in cancer risk. ${ }^{37}$

\section{CONCLUSION}

Defining optimal canonical Wnt signaling regulation to achieve chondrogenic differentiation of MSCs requires evidence capable of resolving specific matters. Such issues are to recognize the appropriate intervention, select the most suitable component of the pathway as a target, and define the intervention's optimal intensity and duration. Data derived from in vitro studies and one animal model elucidate the aforementioned concerns. They indicate that at least a minimum level of canonical Wnt signaling activity is necessary to allow MSC chondrogenesis. Mild activation of the pathway or a low activation intensity is needed, as overexpression of canonical Wnt signaling causes harmful effects on chondrogenic differentiation. Extracellular Wnt inhibitors are not supported in an etiological manner as chondrogenic inducers, while intracellular Wnt activators and specifically Gsk-3 $\beta$ inhibitors are. Prolonged activation of the pathway up to 5 weeks is mandatory for the in- 
duction of chondrogenesis.

These pieces of evidence could contribute to providing insight and reducing uncertainty regarding the role of canonical Wnt signaling in MSC-generated hyaline cartilage restoration.

\section{ACKNOWLEDGEMENTS}

Not applicable

\section{COMPETING INTERESTS}

The authors declare that they have no competing interests.

\section{FUNDING}

No funding received.

\section{AUTHORS’ CONTRIBUTIONS}

The corresponding author conceived of the presented idea. All authors contributed equally to conducting the research and shaping the manuscript.

Submitted: July 05, 2021 EST, Accepted: July 30, 2021 EST 


\section{REFERENCES}

1. Worster AA, Brower-Toland BD, Fortier LA, Bent SJ, Williams J, Nixon AJ. Chondrocyte differentiation of mesenchymal stem cells sequentially exposed to transforming growth factor-beta1 in monolayer and insulin-like growth factor-I in a three-dimensional matrix. J Orthop Res Off Publ Orthop Res Soc. $2001 ; 19: 738-749$.

2. Noth U, Steinert AF, Tuan RS. Technology insight: adult mesenchymal stem cells for osteoarthritis therapy. Nat Clin Pract Rheumatol. 2008;4:371-380.

3. Pittenger MF, Mackay AM, Beck SC, et al. Multilineage potential of adult human mesenchymal stem cells. Science. 1999;284(5411):143-147. doi:10.11 26/science.284.5411.143

4. Zuk PA, Zhu M, Mizuno H, et al. Multilineage cells from human adipose tissue: implications for cellbased therapies. Tis Eng. 2001;7(2):211-228. doi:10.10 $\underline{89 / 107632701300062859}$

5. Gronthos S, Mankani M, Brahim J, Robey PG, Shi S. Postnatal human dental pulp stem cells (DPSCs) in vitro and invivo. Proc Natl Acad Sci U S A. 2000;97(25):13625-13630. doi:10.1073/pnas.2403097 97

6. Phuc PV, Nhung TH, Loan DTT, Chung DC, Ngoc PK. Differentiating of banked human umbilical cord blood-derived mesenchymal stem cells into insulinsecreting cells. In Vitro Cell Dev Biol Anim. 2011;47(1):54-63. doi:10.1007/s11626-010-9356-5

7. Wang HS, Hung SC, Peng ST, et al. Mesenchymal stem cells in the Wharton's jelly of the human umbilical cord. Stem Cells. 2004;22(7):1330-1337. do i:10.1634/stemcells.2004-0013

8. Pelttari K, Steck E, Richter W. The use of mesenchymal stem cells for chondrogenesis. Injury. 2008;39(Suppl 1):S58-S65.

9. Lefebvre V, Bhattaram P. Vertebrate skeletogenesis. Curr Top Dev Biol. 2010;90:291-317.

10. Lories RJ, Corr M, Lane NE. To Wnt or not to Wnt: the bone and joint health dilemma. Nat Rev Rheumatol. 2013;9:328-339.

11. Church V, Nohno T, Linker C, Marcelle C, FrancisWest $\mathrm{P}$. Wnt regulation of chondrocyte differentiation. J Cell Sci. 2002;115(24):4809-4818. do i:10.1242/jcs.00152
12. Hwang SG, Yu SS, Lee SW, Chun JS. Wnt-3a regulates chondrocyte differentiation via c-Jun/AP-1 pathway. FEBS Lett. 2005;579:4837-4842.

13. Yano F, Kugimiya F, Ohba S, et al. The canonical Wnt signaling pathway promotes chondrocyte differentiation in a Sox9-dependent manner. Biochem Biophys Res Commun. 2005;333(4):1300-1308. doi:1 0.1016/j.bbrc.2005.06.041

14. Moreira AR, Mardones R, Pritzker K, Wijnen AJ, Galindo MA, Heras FL. Dickkopf-1 reduces hypertrophic changes in human chondrocytes derived from bone marrow stem cells. Gene. 2019;687:228-237.

15. Zhang Y, Huang X, Yuan Y. MicroRNA-410 promotes chondrogenic differentiation of human bone marrow mesenchymal stem cells through downregulating Wnt3a. Am J Transl Res. 2017;9(1):136-145.

16. Huang X, Zhong L, Hendriks J, Post JN, Karperien $M$. The effects of the WNT-Signaling modulators BIO and PKF118-310 on the chondrogenic differentiation of Human Mesenchymal Stem Cells. Int J Mol Sci. 2018;19:561.

17. Huang T, Zhou Y, Wang J, Cao Y, Hang DH. MiR-26b regulates cartilage differentiation of bone marrow mesenchymal stem cells in rats through the $\mathrm{Wnt} / \beta$-catenin signaling pathway. European Review for Medical and Pharmacological Sciences. 2019;23:5084-5092.

18. Tanthaisong $P$, Imsoonthornruksa $S$, Ngernsoungnern A, Ngernsoungnern P, KetudatCairns M, Parnpai R. Enhanced Chondrogenic Differentiation of Human Umbilical Cord Wharton's Jelly Derived Mesenchymal Stem Cells by GSK-3 Inhibitors. PLoS ONE. 2017;12(1):e0168059.

19. Jothimani G, Di Liddo R, Pathak S, Piccione M, Sriramulu $S$, Banerjee A. Wnt signaling regulates the proliferation potential and lineage commitment of human umbilical cord derived mesenchymal stem cells. Mol Biol Rep. 2020;47(2):1293-1308. doi:10.100 7/s11033-019-05232-5

20. Eslaminejad MB, Karimi N, Shahhoseini M. Enhancement of Glycosaminoglycan-Rich Matrix Production in Human Marrow-Derived Mesenchymal Stem Cell Chondrogenic Culture, by Lithium Chloride and SB216763 Treatment. CELL JOURNAL (Yakhteh). 2011;13(2):117-126. 
21. Baghaban Eslaminejad MR, Fallah N. Small Molecule- BIO Accelerates and Enhances MarrowDerived Mesenchymal Stem Cell in Vitro Chondrogenesis. Iran J Med Sci. 2014;39(2):107-116.

22. Yang Z, Zou Y, Guo XM, et al. Temporal activation of $\beta$-Catenin signaling in the Chondrogenic Process of Mesenchymal Stem Cells Affects the Phenotype of the Cartilage Generated. STEM CELLS AND DEVELOPMENT. 2012;21(11).

23. Zhang Y, Guo W, Wang M, et al. Co-culture systems-based strategies for articular cartilage tissue engineering. J Cell Physiol. 2018;233:1940-1951.

24. Li Z, Wang Y, Xiang S, et al. Chondrocytes -derived exosomal miR-8485 regulated the Wnt/ $\beta$ catenin pathways to promote chondrogenic differentiation of BMSCs. Biochemical and Biophysical Research Communications. 2020;523(2):506-513.

25. Li S, Macon ALB, Jacquemin M, Stevens MM, Jones JR. Sol-gel derived lithium-releasing glass for cartilage regeneration. Journal of Biomaterials Applications. 2017;32(1):104-113.

26. Schizas NP, Savvidou O, Diamantopoulou K, Papadakis S, Papagelopoulos PJ, Triantafyllopoulos IK. The combination of microfracture with induction of Wnt / $\beta$ - Catenin pathway, leads to enhanced cartilage regeneration. J Orthop Surg Res. 2019;14(1):428. doi:10.1186/s13018-019-1484-3

27. MacDonald BT, Tamai K, He X. Wnt/ $\beta$-catenin signaling: Components, mechanisms, and diseases. Dev Cell. 2009;17(1):9-26.

28. Bovolenta P, Esteve P, Ruiz JM, Cisneros E, LopezRios J. Beyond Wnt inhibition: new functions of secreted Frizzled-related proteins in development and disease. Journal of cell science. 2008;121(6):737-746. doi:10.1242/jcs.026096

29. Ellwanger K, Saito H, Clément-Lacroix P, et al. Targeted disruption of the Wnt regulator Kremen induces limb defects and high bone density. Mol Cell Biol. 2008;28(15):4875-4882. doi:10.1128/mcb.0022 $\underline{2-08}$
30. Fischer L, Boland G, Tuan RS. Wnt-3A enhances bone morphogenetic protein-2-mediated chondrogenesis of murine C3H10T1/2 mesenchymal cells. J Biol Chem. 2002;277(34):30870-30878. doi:10.1 074/jbc.m109330200

31. Hartmann C, Tabin CJ. Dual roles of Wnt signaling during chondrogenesis in the chicken limb. Development. 2000;127(14):3141-3159. doi:10.1242/d ev.127.14.3141

32. Filali M, Cheng N, Abbott D, Leontiev V, Engelhardt JF. Wnt-3A/beta-catenin signaling induces transcription from the LEF-1 promoter. Arthritis Rheum. 2002;46(11):2867-2877.

33. Enomoto-Iwamoto M, Kitagaki J, Koyama E, et al. The Wnt antagonist Frzb-1 regulates chondrocyte maturation and long bone development during limb skeletogenesis. J Biol Chem. 2002;277(36):33398-33410.

34. Green JD, Tollemar V, Dougherty M, et al. Multifaceted signaling regulators of chondrogenesis: Implications in cartilage regeneration and tissue engineering. Genes \& Diseases. 2015;2:307-327.

35. Burgess AW, Faux MC, Layton MJ, Ramsay RG. Wnt signaling and colon tumorigenesis-a view from the periphery. Exp Cell Res. 2011;317(19):2748-2758. doi:10.1016/i.yexcr.2011.08.010

36. Deng Q, Li P, Che M, et al. Activation of hedgehog signaling in mesenchymal stem cells induces cartilage and bone tumor formation via Wnt/ $\beta$-Catenin. Life. 2019;4;8:e50208.

37. Mason JJ, Williams BO. SOST and DKK: Antagonists of LRP Family Signaling as Targets for Treating Bone Disease. Journal of Osteoporosis. 2010;2010:460120. 